\title{
Structural change and growth accelerations in Asia and Latin America: a new sectoral data set
}

\author{
Marcel P. Timmer • Gaaitzen J. de Vries
}

Received: 1 February 2008/Accepted: 23 May 2008/Published online: 13 June 2008

(C) The Author(s) 2008

\begin{abstract}
Recent studies of economic growth have moved from explaining average trends in long-term growth to study growth accelerations and decelerations. In this paper we argue that the standard shift-share analysis is inadequate to measure the contribution of sectors to accelerations in productivity. We present a modified shift-share method, which takes account of surplus labour in agriculture and accounts for the contribution to growth from expanding sectors. We apply this novel methodology to the GGDC 10-sector database, which is a new data set with annual time series of value added and persons employed for the ten main sectors of the economy. The data set covers 19 countries in Asia and Latin America spanning the period from 1950 to 2005 . We find that growth accelerations are explained by productivity increases within sectors, not by reallocation of employment to more productive sectors. Challenging conventional wisdom, productivity improvement in market services is more important than productivity growth in manufacturing.
\end{abstract}

Keywords Structural change - Shift-share analysis - Growth accelerations · Sectoral database

JEL Classification $\quad \mathrm{C} 80 \cdot \mathrm{N} 10 \cdot \mathrm{O} 10$

\section{Introduction}

Recent studies of economic growth have moved from explaining average trends in long-term growth to study the determinants of growth accelerations and growth

M. P. Timmer $(\bowtie) \cdot$ G. J. de Vries

Department of Economics and Business, and Groningen Growth and Development Centre,

University of Groningen, Zernike Complex, P.O. Box 800, 9700 AV Groningen,

The Netherlands

e-mail: m.p.timmer@rug.nl 
decelerations, because of the great instability in growth rates within countries. Very few countries have experienced consistently high growth rates over long periods. Rather, the more typical pattern is that countries experience phases of growth, stagnation, or decline of varying length. A study of these separate periods seems more revealing for a study of the determinants of growth than a long-period average (Pritchett 2000). This raises the natural question which sectors in the economy contribute most to accelerations and decelerations in growth. For example, Jones and Olken (2008) suggest that employment reallocation to more productive sectors lies behind accelerations and decelerations of growth in many developing countries. Because of missing sectoral data, they are unable to test this hypothesis. In this paper, we provide empirical evidence on the significance of various sectors in generating aggregate productivity growth by introducing a novel shift-share analysis and by applying this method to a new sectoral database for 19 countries in Asia and Latin America, spanning the period from 1950 to 2005.

Each sector can contribute to aggregate growth in two ways: by productivity growth within the sector (the within-effect) and by expanding its share in aggregate inputs (the between- or shift-effect). To measure these contributions we modify a standard tool in an economic historians' tool-box: the shift-share analysis introduced by Fabricant (1942). The shift-share analysis is used in many studies to measure the contribution of structural change to aggregate growth. For example, it features prominently in the discussion about the extent of Britain's decline relative to Germany and the US since the end of the nineteenth century (Broadberry 1998). Unfortunately, the interpretation of results from the traditional shift-share method is not straightforward [see for example the discussion between Broadberry and Crafts (2003) and Booth (2003)].

We propose two modifications to the traditional shift-share analysis, which make its results more useful. First, the standard method does not allow for disequilibria in factor markets in which average productivity differs from marginal productivity. Especially in early stages of development, the agricultural sector is characterised by wide-spread disguised unemployment (Dennison 1967; Broadberry 1998). We use estimates of the shadow price of labour to measure this wedge and adjust the shiftshare method accordingly. This adjustment increases the measured importance of structural change to growth. Second, the traditional method does not properly account for differences in productivity levels between sectors. For example, the expansion of a low-productive sector such as government services would show up as being positive for aggregate growth. We account for differences in productivity levels between sectors and derive more meaningful measures of the contribution of particular sectors to aggregate productivity growth.

This novel decomposition method is used to study the sectoral contribution to growth accelerations and growth collapses in Asia and Latin America since 1950. We apply the decomposition to a new database called the GGDC 10-sector database. This database provides sectoral detail to the long-run macro data in Maddison (2003) and is a complement to the sectoral database for OECD countries by van Ark (1996). It covers 19 countries in Asia and Latin America and includes employment and value added data on agriculture, four industrial sectors, three market services sectors and government. We find that resource reallocation is not the main driver of accelerations 
and decelerations in aggregate economic growth. Productivity improvements within sectors, in particular within manufacturing and market services, appear to be much more important for growth in Asia and Latin America since the 1950s.

The remainder of this paper is structured as follows. In Sect. 2 we present the new decomposition method. Section 3 describes data contents, selection criteria and sources of the sectoral data set for developing countries. Sectoral contributions to growth accelerations are presented in Sect. 4. Finally, Sect. 5 concludes.

\section{Decomposition method}

Since long, the importance of sectoral development patterns for economic growth has been recognised. In this work, changes in the sectoral composition of production and employment and their interaction with the pattern of productivity growth feature prominently. Technological change typically takes place at the level of industries and induces differential patterns of sectoral productivity growth. At the same time, changes in domestic demand and international trade patterns drive a process of structural transformation in which labour, capital and intermediate inputs are continuously relocated between firms, sectors and countries (Kuznets 1966; Chenery et al. 1986; Harberger 1998). One of the best documented patterns of structural change is the shift of labour and capital from production of primary goods to manufacturing and services. Another finding is that the level and growth rate of labour productivity in agriculture is considerably lower than in the rest of the economy (at least at low levels of income), reflecting differences in the nature of the production function, in investment opportunities and in the rate of technical change (Syrquin 1984; Crafts 1984). Together these findings suggest a potentially important, albeit temporary, role for resource allocation from lower to higher productive activities to boost aggregate productivity growth.

This potential growth bonus was already identified in classical dual economy models such as Lewis (1954) and Fei and Ranis (1964). ${ }^{1}$ These models presumed that in early stages of development, agricultural labourers shift to the industrial sector without any reduction in total agricultural output. The existence of this source of inefficiency can be explained by the immobility of agricultural labour vis-à-vis the industrial sector caused by the discrepancy between private costs, approximated by the average product in agriculture, and social costs. ${ }^{2}$ Differences in the potential for structural change have featured prominently in explanations of differential growth within European countries in the post-WW-II period (Dennison 1967; Maddison 1987; Temin 2002). However, the quantification of its importance has

\footnotetext{
${ }^{1}$ Lewis' dual economy was not based on a sharp distinction between agriculture and industry. Rather he emphasizes differences between traditional and modern activities which coexist in all sectors of the economy. Parts of agriculture such as plantations and other export oriented activities can have high labour productivity levels. On the other hand, family-based handicrafts in industry and petty trade in services are activities with relatively low levels of labour productivity.

2 Combined models of household behaviour and rural labour markets have shown that this disequilibrium is independent of the assumptions of missing rural labour markets, but crucially depends on the response of other family workers to the removal of one worker (see Rosenzweig 1988 for an overview).
} 
been hampered by a clear methodology to measure the effect of structural change on aggregate productivity growth.

The standard method to measure this is the shift-share decomposition originating from Fabricant (1942). This method is part of the standard tool kit of economic historians and used in many studies. ${ }^{3}$ One major problem of the traditional shiftshare method is the assumption that productivity growth within each sector is not affected by structural change. Clearly productivity growth rates are affected since, for example, productivity growth in agriculture is largely possible due to the employment reallocation to manufacturing and services. For example, labour productivity in South Korean agriculture increased 5\% annually during the period 1963-2005. It is not likely that this high growth rate could have been sustained when in 2005 still $63 \%$ of the population was working in agriculture, as in $1963 .{ }^{4}$ Broadberry (1998) argued that the shift-share analysis should be modified by assuming that the marginal productivity of workers leaving shrinking sectors is equal to zero. Although this adjustment overestimated the effect of sectoral expansions (Booth 2003), we propose an extension and improvement of the traditional shift-share analysis in a similar direction without overstating sectoral employment reallocation.

\subsection{The traditional shift-share analysis}

The simplest way to model the contribution of sectors to aggregate growth is by assuming a one-country, two-sector, two-period model and decompose the productivity change between period 0 and $T$ into the contribution of two sectors $i$. Let $Y_{i}$ denote value added in sector $i, L_{i}$ denote employment, and superscripts 0 and $T$ the beginning and end of the period $[0, T]$. Then aggregate labour productivity $(P)$ at time $T$ can be written as:

$$
P^{T}=\frac{Y^{T}}{L^{T}}=\frac{Y_{1}^{T}+Y_{2}^{T}}{L^{T}}=\frac{Y_{1}^{T}}{L_{1}^{T}} \frac{L_{1}^{T}}{L^{T}}+\frac{Y_{2}^{T}}{L_{2}^{T}} \frac{L_{2}^{T}}{L^{T}}=P_{1}^{T} S_{1}^{T}+P_{2}^{T} S_{2}^{T}
$$

with $P_{i}$ denoting the labour productivity level in sector $i$ and $S_{i}$ the share of each sector in total employment.

Using (1), the difference in aggregate labour productivity levels at time 0 and $T$ can be written as:

$$
P^{T}-P^{0}=\left(P_{2}^{T}-P_{2}^{0}\right) S_{2}^{T}+\left(P_{1}^{T}-P_{1}^{0}\right) S_{1}^{T}+\left(S_{2}^{T}-S_{2}^{0}\right) P_{2}^{0}+\left(S_{1}^{T}-S_{1}^{0}\right) P_{1}^{0}
$$

or alternatively,

$$
P^{T}-P^{0}=\left(P_{2}^{T}-P_{2}^{0}\right) S_{2}^{0}+\left(P_{1}^{T}-P_{1}^{0}\right) S_{1}^{0}+\left(S_{2}^{T}-S_{2}^{0}\right) P_{2}^{T}+\left(S_{1}^{T}-S_{1}^{0}\right) P_{1}^{T}
$$

To make the decomposition invariant to a particular base, period averages can be used as weights:

\footnotetext{
${ }^{3}$ See for applications, e.g. Broadberry and Crafts (2003), Chenery et al. (1986), Crafts (1993), Field (2006) and van Ark (1996).

${ }^{4}$ This point was first raised by Dennison (1967). See also Broadberry (1998) who calls this assumption "simply not credible" (p. 388).
} 


$$
P^{T}-P^{0}=\left(P_{2}^{T}-P_{2}^{0}\right) \bar{S}_{2}+\left(P_{1}^{T}-P_{1}^{0}\right) \bar{S}_{1}+\left(S_{2}^{T}-S_{2}^{0}\right) \bar{P}_{2}+\left(S_{1}^{T}-S_{1}^{0}\right) \bar{P}_{1}
$$

with a bar indicating the arithmetic average over period $[0, T]$. In a multi-sector setting the decomposition becomes as follows:

$$
P^{T}-P^{0}=\sum_{i=1}^{n}\left(P_{i}^{T}-P_{i}^{0}\right) \bar{S}_{i}+\sum_{i=1}^{n}\left(S_{i}^{T}-S_{i}^{0}\right) \bar{P}_{i}
$$

It follows that aggregate productivity growth can be decomposed into withinsectoral productivity growth (the first term on the right-hand side which we call the "within-effect", also known as "intra-effect") and the effects of changes in the sectoral allocation of labour (the second term, which we call the "between-effect", also known as the "shift-effect"). The within-effect is positive when labour productivity growth in sector $i$ is positive; it is negative when labour productivity growth in $i$ is negative. The contribution of the shift-effect can also be either positive or negative, depending on whether a sector is expanding or shrinking. ${ }^{5}$

\subsection{The modified shift-share analysis}

The split between within- and between-effects in the standard decomposition is not undisputed. It is based on the assumption that marginal and average labour productivity in a sector are equal, or put otherwise, that labour productivity growth is independent of the changes in employment. However, the existence of surplus labour or disguised employment in the agricultural sector is a typical phenomenon in many countries in early stages of development (Rosenzweig 1988; Fei and Ranis 1997). As long as marginal productivity is below average productivity, a decline in the number of agricultural workers will by definition raise the average labour productivity level in agriculture. Using (5), the difference between average and marginal productivity in agriculture will end up in the within-effect, whereas its effect actually arises from the shift of labour in response to the opening up of new employment opportunities elsewhere in the economy. This suggests that (part of) the within-contribution of agriculture should be allocated to the between-contribution of other sectors. ${ }^{6}$ To accommodate this important shortcoming, we modify the traditional decomposition, inspired by the more informal approach of Dennison (1967).

Suppose that the number of workers in agriculture is declining during the period $[0, T]$. We define two groups of workers: those who stay within agriculture $\left(L^{T}\right)$ and those who leave $\left(L^{0}-L^{T}\right)$. Those who leave are assumed to be marginal workers with a lower productivity than those who stay behind. To generalize the case, let $\varepsilon$ be the ratio of the marginal and average labour productivity of labour in the base

\footnotetext{
${ }^{5}$ Salter (1960) provides an alternative to this additive decomposition and proposes a multiplicative decomposition. However, the major disadvantage of the latter is that sectoral contributions to aggregate growth cannot be assessed which is an important use of the decomposition in this paper.

${ }^{6}$ Similarly, it might be the case that the agricultural sector acts as a buffer in hard times and absorbs labour which is put out of employment in other sectors of the economy. Crisis periods such as the one following the Asian financial crisis in 1997 may cause such counter effects. But as the effects are short term rather than long term, this situation is not accounted for.
} 
year, being in between 0 and $1 .^{7}$ We calculate the average labour productivity of each of the two groups at time 0 . The average labour productivity level of the workers who leave is given by $\varepsilon P^{0}$. The average productivity level at time 0 of those workers who stay in the agricultural sector (denoted by $\tilde{P}^{0}$ ), is then given by:

$$
\tilde{P}^{0}=\frac{Y^{0}-\varepsilon P^{0}\left(L^{0}-L^{T}\right)}{L^{T}}
$$

In the case that $\varepsilon=1$, as in the standard shift-share method, each worker leaving the sector will cause a cut in sectoral output equal to the average productivity of those who stay behind such that $\tilde{P}^{0}=P^{0}$. When $\varepsilon<1$, we assume-in accordance with the Lewis hypothesis - that the productivity of those who leave the agricultural sector is lower than of those who stay behind. As a result the average productivity of those workers remaining in agriculture increases. In the most extreme case, the decline in the number of workers in agriculture has no effect on agricultural output, $\varepsilon=0$.

To measure the contribution of agriculture to aggregate productivity growth, we should only include agricultural productivity growth not due to the emigration of marginal workers. This is given by $\left(P^{T}-\tilde{P}^{0}\right) \bar{S}$. The remainder of the original within-contribution of agriculture, $\left(\tilde{P}^{0}-P^{0}\right) \bar{S}$, is allocated to the between-effect (see Appendix for details). ${ }^{8}$ Compared to the traditional shift-share, this adjustment will result in a greater contribution of structural change (the between-effect) to aggregate growth.

The shift-share method is often used to decompose aggregate productivity growth into between- and within-effects. Occasionally it is also used to measure the growth contribution of individual sectors and to answer questions like: what was the contribution of the manufacturing sector to aggregate labour productivity growth? ${ }^{9}$ However, the standard method is not well suited to answer questions like these. In the traditional procedure, all expanding sectors contribute positively to aggregate productivity growth, even when they have below-average productivity levels. Consider, for example, the expansion of employment in government services at the expense of manufacturing. And assume that the productivity level in government services is below average, while manufacturing labour productivity is above

\footnotetext{
7 This ratio will be determined on the basis of a piecewise linear production function, see the Appendix.

${ }^{8}$ Others have suggested similar, but less general modifications to deal with surplus labour. For example, Broadberry (1998) assumes zero marginal productivity $(\varepsilon=0)$ not only in agriculture but in all sectors which have a declining share in employment. The assumption of zero marginal productivity is rather extreme given available evidence. Moreover, Broadberry's assumption is not consistent with the surpluslabour hypothesis which is not about shares of labour but about absolute amounts. Sectors for which employment shares are declining, but absolute number of workers are increasing are typical of rapidly expanding economies, such as in Asia. For example, the agricultural share in the total labour force in Thailand has already been declining since the beginning of the 1960s, but the absolute amount of agricultural workers has only decreased since the end of the 1980s due to high population growth rates. Similar lags are found for other countries. Therefore the Broadberry (1998) decomposition method overstates the shift-effect (see also Booth 2003). One can argue that in sectors like trade and transportation services, marginal and average productivity might diverge as well due to a significant amount of informal activities in poor countries. Ideally, this should be taken into account, but statistics on informal activities are scarce, especially at the sectoral level, and not comparable across countries. This remains an important issue for further research.
}

9 See for example Crafts (1993). 
average. As a result of the shift in employment shares, aggregate productivity growth will become lower. Nevertheless, as measured in the traditional method, the contribution of the expansion of government services is positive. In the modified method we therefore adjust the between-effect of an expanding sector to take into account its relative productivity level. To this end, we divide sectors into expanding and shrinking and calculate the between-effect relative to the average productivity level of the shrinking sectors. The decomposition in (5) is modified as follows:

$$
P^{T}-P^{0}=\sum_{K, J}\left(P_{i}^{T}-P_{i}^{0}\right) \bar{S}_{i}+\sum_{K}\left(S_{i}^{T}-S_{i}^{0}\right)\left(\bar{P}_{i}-\bar{P}_{J}\right)
$$

With $K$ the set of expanding sectors and $J$ the set of shrinking sectors, and with average labour productivity in shrinking sectors defined as:

$$
\overline{P_{J}}=\frac{\sum_{i \in J}\left(S_{i}^{T}-S_{i}^{0}\right) \overline{P_{i}}}{\sum_{i \in J}\left(S_{i}^{T}-S_{i}^{0}\right)}
$$

This allows us to make a meaningful decomposition of aggregate labour productivity growth into the contributions of various sectors. In our decomposition, only the expansion of sectors with above-average productivity levels contributes positively to aggregate productivity growth. The expansion of sectors with belowaverage productivity levels contributes negatively to aggregate productivity growth. The Appendix provides a more detailed exposition of the modified shift-share analysis.

\subsection{A comparison of the traditional and the modified shift-share analysis}

In Table 1, we present an example using the traditional and the modified shift-share analysis to illustrate the differences between the two. This table shows the withinand between-sector contributions to growth in Korea during 1963-2005. Method I is the traditional shift-share decomposition method. Method II is the modified decomposition method with country-specific estimates of surplus labour. ${ }^{10}$ In addition, in Method III we make the adjustment for the effect of shrinking and expanding sectors as described above.

Average annual productivity growth in South Korea during 1963-2005 was $4.5 \%$. Using the traditional decomposition method (Method I), the total withinsector contribution to growth is $3.6 \%$ points (see last row "Total"). The contribution of structural change is only $0.8 \%$ points. If we adjust for surplus labour in agriculture, part of the within-contribution of agriculture is relocated to the between-contribution of other sectors. The results are shown under the columns of Method II. This adjustment increases the effects of structural change to $1.0 \%$ points.

Now look at the contribution of individual sectors. For example, during 1963 to 2005 the provision of market services strongly expanded. The traditional method (Method I) estimates that the growth contribution from this sector was $1.3 \%$ points. The expansion of this sector (between-effect) was responsible for $0.7 \%$ points while productivity improvements within the sector contributed another $0.6 \%$ points. However, the level of productivity in market services is much lower than in the rest

\footnotetext{
${ }^{10}$ For Korea, $\varepsilon=0.156$, see Sect. 3 for a further discussion of these estimates.
} 
Table 1 Comparison of traditional and modified shift-share method, South Korea 1963-2005, in percentage points contribution to aggregate labour productivity growth

\begin{tabular}{|c|c|c|c|c|c|c|c|c|c|}
\hline & \multicolumn{3}{|c|}{ Method I } & \multicolumn{3}{|c|}{ Method II } & \multicolumn{3}{|c|}{ Method III } \\
\hline & Within & Between & Total & Within & Between & Total & Within & Between & Total \\
\hline Agriculture & 0.9 & -1.0 & 0.0 & 0.7 & -1.0 & -0.2 & 0.7 & 0.0 & 0.7 \\
\hline Other industries & 0.5 & 0.1 & 0.6 & 0.5 & 0.1 & 0.6 & 0.5 & 0.1 & 0.6 \\
\hline Manufacturing & 1.6 & 0.7 & 2.3 & 1.6 & 0.8 & 2.3 & 1.6 & 0.6 & 2.1 \\
\hline Market services & 0.6 & 0.7 & 1.3 & 0.6 & 0.8 & 1.4 & 0.6 & 0.3 & 0.9 \\
\hline Non-market services & 0.0 & 0.2 & 0.2 & 0.0 & 0.3 & 0.3 & 0.0 & 0.1 & 0.1 \\
\hline Total & 3.6 & 0.8 & 4.5 & 3.4 & 1.0 & 4.5 & 3.4 & 1.0 & 4.5 \\
\hline
\end{tabular}

Method I is the traditional shift-share method. Method II is the decomposition method with countryspecific estimate of surplus labour (for Korea, $\varepsilon=0.156$ ). Method III is our preferred decomposition method with an additional adjustment for the effect of shrinking and expanding sectors. "Other industries" include mining, public utilities, and construction. "Market services" include wholesale and retail trade, transport and communication and financial services. "Non-market services" include community, social and personal services and government services. Numbers may not add up due to rounding. [Source: calculations based on the GGDC 10-sector database, see Timmer and de Vries (2007)]

of the economy. Once we correct for this, as in Method III, the total contribution of this sector drops to $0.9 \%$ points.

Conversely, the contribution of agriculture to aggregate productivity growth is negative in the traditional method. In the modified shift-share analysis, the contribution of productivity growth within agriculture is lower (see the change in within-effects between Methods I and II), but the between-effect is higher (compare Methods II and III). We find that agricultural in total contributed $0.7 \%$ points to aggregate productivity growth, while in the traditional shift-share analysis, the total contribution of agriculture to economic growth is zero. The latter is not in line with the consensus that dynamic growth in agriculture has been an important stimulus for the economic development of South Korea (see e.g. Fei and Ranis 1997).

In Sect. 4, we will decompose all periods of accelerations and decelerations in economic growth in Asia and Latin America by using the modified decomposition method. First we discuss the data set in the next section.

\section{The GGDC 10-sector database}

Comparative studies of sectoral growth have been hampered by the lack of a largescale international database on output and productivity trends by sector in developing countries. In this section we present the Groningen Growth and Development Centre (GGDC) 10-sector database which is the first database to provide long-term series on sectoral developments. ${ }^{11}$ The database is constructed on

\footnotetext{
${ }^{11}$ Various international organizations such as the World Bank, the United Nations, the Asian Development Bank, and also the Oxford Latin American Economic History Database collect sectoral data for developing countries and make it publicly available. But series are often short (starting only in the 1980s or 1990s), not consistent over time and across countries, and the series have little sectoral detail. In our working paper version (Timmer and de Vries 2007) we compare the GGDC 10-sector database with other publicly available sectoral data sets.
} 
the basis of an in-depth study of available statistical sources on a country-bycountry basis. We discuss the contents of the database, the selection procedure of the sources, and the methods used to ensure intertemporal, international and internal consistency. Compliance with consistency requirements is important to ensure the usefulness of the database in long-term analyses of growth and productivity. We also present country-specific estimates of surplus labour in agriculture.

\subsection{Contents of the data set}

Below, Table 2 gives an overview of the contents of the GGDC 10-sector database. The data set consists of ten Asian countries and nine Latin American countries. It includes annual data on gross value added at both current and constant prices from 1950 to 2005. It also includes data on persons employed, which allows the derivation of labour productivity (value added per worker) trends. The database covers the ten main sectors of the economy as defined in the international standard industrial classification, revision 2 (ISIC rev. 2). Together these ten sectors cover the total economy. Data and detailed documentation of sources and methods are publicly available through http://www.ggdc.net/dseries/10-sector.html.

Table 2 The GGDC 10-sector database

Countries included

Asia

Latin America

Sectors (ISIC rev. 2)

Time period (annual)

Variables

Principal sources
Hong Kong (China), India, Indonesia, Japan, Korea (Rep. of), Malaysia, Philippines, Singapore, Taiwan, Thailand

Argentina, Bolivia, Brazil, Chile, Colombia, Costa Rica, Mexico, Peru, Venezuela (Rep. Bol.)

Agriculture, hunting, forestry and fishing

Mining and quarrying

Manufacturing

Electricity, gas and water

Construction

Wholesale and retail trade, hotels and restaurants

Transport, storage and communication

Finance, insurance, real estate and business services

Community, social and personal services

Government services

1950-2005

Gross value added at constant prices

Gross value added at current prices

Persons employed

National accounts

Population censuses

Business surveys

Labour force surveys 


\subsection{Construction of variables}

Gross value added in current and constant prices is taken from the national accounts of the various countries. As these have all been compiled according to the UN System of National Accounts, international comparability is high, in principle. However, national statistical institutes frequently change their methodologies. In the national accounts, GDP series are periodically revised which includes changes in the coverage of activities (for example after a full economic census has been carried out and "new" activities have been discovered), changes in the methods of calculation (for example the inclusion of software expenditures as investment rather than intermediate consumption), and changes in base year of the prices used for calculating volume growth rates. ${ }^{12}$ For sectoral GDP our general approach is to start with GDP levels for the most recent available benchmark year, expressed in that year's prices, from the national accounts provided by the National Statistical Institute or Central Bank. Historical national accounts series were subsequently linked to this benchmark year. ${ }^{13}$ This linking procedure ensures that growth rates of individual series are retained although absolute levels are adjusted according to the most recent information and methods.

Employment in our data set is defined as "all persons employed", thus including all paid employees, but also self-employed and family workers. ${ }^{14}$ Labour input is normally not available from a country's national accounts as they are not part of the System of National Accounts. ${ }^{15}$ Two different primary sources of employment exist, namely labour force surveys (LFS) with data collected at the household level, and business surveys which are based on firm-level questionnaires. Both have their advantages and disadvantages as a source for annual sectoral employment trends.

The LFS is a comprehensive and well-established source with substantive international harmonization of concepts as it uses definitions set out by the International Labour Organization (ILO), although sampling size and techniques may still differ substantially between countries. They cover employees as well as self-employed and family-labour. The main problem of labour force surveys is the limited consistency with output data from the national accounts, especially at the sectoral level due the relatively small sample size. In addition, the sample is sometimes restricted to particular regional areas, such as urban areas.

Information from business surveys is often more consistent with value added measures in the national accounts, as output series for the national accounts are also based on this source. However, while the coverage by business surveys is reasonably accurate for goods producing industries, it is not always for services. Moreover business surveys typically only cover firms who surpass a certain

\footnotetext{
${ }^{12}$ In most developing countries a fixed-base Laspeyres volume index is used and this base is usually updated every 5 or 10 years.

${ }^{13}$ Because of the application of fixed-base Laspeyres volume indexes by most statistical offices, linked sectoral GDP does not add up to total GDP for earlier periods.

${ }^{14}$ Ideally, hours worked should be collected as well, but this datum is irregular and sparse and only covers the formal sector.

${ }^{15}$ Most OECD countries nowadays provide sectoral employment figures alongside GDP in the national accounts but this practice has not been adopted by less-developed countries.
} 
threshold (for example, $>20$ employees or above a certain turnover level). This excludes smaller firms, which are especially abundant in developing countries. Another limitation is that data on self-employed and unpaid family members are usually not collected. This is problematic for sectors like agriculture and informal parts of the economy, where these categories make up a significant share of total employment. Business surveys are therefore not well suited to provide employment statistics by sectors that cover the total economy.

Therefore we often use an alternative source based on household questionnaires but with a much larger coverage than the samples of the LFS: the population census. This ensures full coverage of the working population and a much more reliable sectoral breakdown than from the LFS. ${ }^{16}$ However, typically population censuses are quinquennial or decennial and cannot be used to derive annual trends. Therefore we use the population census to indicate absolute levels of employment, and use LFS and business surveys to indicate trends in between. This is the general strategy followed for most countries, but not for all. ${ }^{17}$

\subsection{Consistency}

In constructing the database, we paid careful attention to three checks on consistency, namely intertemporal consistency, international consistency, and internal consistency. Our time series of gross value added and employment are consistent over time (that is, intertemporal consistent). Through our linking procedure as described above, major breaks in the series have been repaired. International consistency of the crosscountry sectoral data is ensured through the system of national accounts for value added, the employment concept of persons engaged and the use of a harmonized sectoral classification. We classify activities into ten sectors, using the ISIC rev. 2. The industrial classification used in the national primary data sources is based on this classification or is directly related to it.

Finally, for the derivation of meaningful productivity measures, the labour input and output measures should cover the same activities (that is, being internally consistent). As we use persons employed as our employment concept rather than employees, and base our employment numbers on large-scale surveys, overlap in coverage of the employment statistics and value added from the national accounts is maximized. However, a notable exception is the own-account production of housing services by owner-occupiers. For this an imputation of rent is made and added to GDP in many countries, according to the System of National Accounts. This imputed production does not have an employment equivalent and should preferably

\footnotetext{
${ }_{16}$ Official population censuses data for 1950, 1960 and 1970 appear to be unreliable in Latin America. In order to remedy this problem we used the harmonized population census results published by PREALC (1982). This study makes adjustments in order for the population censuses to be reliable and comparable within and between countries (for example correcting for age limitations, reference periods, ISIC revisions, workers entering the labour market, unspecified workers and on the underestimation of agricultural workers).

17 The sources and methods document available at http://www.ggdc.net/dseries/10-sector.html provides a detailed discussion of the construction of the employment and value added series on a country-by-country basis.
} 
not be included in output for the purposes of labour productivity comparisons. ${ }^{18}$ Therefore, the GGDC 10-sector database presents separate series for imputed rents. In our decomposition analysis we excluded imputed rents.

\subsection{Surplus labour in agriculture}

In addition to time series of value added and employment from the GGDC 10-sector database, the application of the modified shift-share analysis requires estimates of the ratio of marginal and average labour productivity in agriculture $\left(\varepsilon_{\mathrm{A}}\right)$ across countries. Because we cannot measure the wedge between marginal and average productivity of labour directly, certain assumptions are required. Our proxy of this ratio is based on a study by Coelli and Rao (2005), who calculates implicit shadow prices of inputs in agriculture based on data envelopment analysis (DEA). In DEA a global production frontier is derived based on observations of quantities of inputs and outputs for a large set of countries. This allows the derivation of implicit (or shadow) prices of inputs, which measure marginal productivity. ${ }^{19}$ Table 3 in Appendix shows our estimates of the ratio of marginal to average labour productivity in Asian and Latin American agriculture. We find no clear patterns in the ratio of marginal to average productivity across countries. This might result from a complicated interaction between cross-country differences in GDP per capita, labour intensity of agricultural production, and the protection of the agricultural sector. The estimate is only available as an average over the period 1980-2000 and we have to assume that it is constant over time. However, especially when longer time periods are considered, this ratio is likely to change.

\section{Sectoral origins of accelerations and decelerations in economic growth}

We use the new decomposition method and the GGDC 10-sector database to study sectoral origins of growth accelerations and decelerations in Asia and Latin America. First, we use the filter from Hausmann et al. (2005) to determine periods of accelerations and decelerations in growth, and next we perform the modified shift-share analysis. The modified shift-share analysis decomposes growth in GDP per worker into improvements within industries and improvements due to the reallocation of labour across industries. In the decomposition, we account for surplus labour. Furthermore, expanding sectors only contribute to productivity growth if their productivity level is higher than the economy's average, as described in Sect. 2.

The functioning of the filter from Hausmann et al. (2005) is explained in the Appendix. The filter selects growth accelerations as 5-year periods where average annual growth is high and more than $3 \%$ points above previous 5-year period

\footnotetext{
18 Typically, imputed rents are included in the output of the financial and business services sector and frequently increase output in this sector by $50 \%$ or more without any labour input equivalent. Worse, this percentage varies over time and across countries.

19 See the Appendix for an elaboration.
} 
average annual growth. In a similar manner, decelerations are selected using the filter. Our results indicate that the number of accelerations and decelerations in GDP per worker is large (see Table 4, Appendix). In total, Asian and Latin American countries experienced 28 accelerations in GDP per worker and 19 decelerations from 1950 to 2005 . The number of accelerations, as well as the start year of growth accelerations across countries is similar to Hausmann et al. (2005). ${ }^{20}$

Recently, various authors have studied sources of growth accelerations and decelerations that occur in countries over time. ${ }^{21}$ Using growth accounting techniques, Jones and Olken (2008) conclude that factor accumulation and utilization explain no more than one-third of the total change in output growth during growth accelerations and growth decelerations in a large country sample. This leaves total factor productivity growth as the primary explanation of changes in output growth. Aggregate productivity growth comes from resource reallocation from less to more productive industries or from productivity improvements within industries. Jones and Olken (2008) find large moves of labour into manufacturing during high-growth episodes and large moves out of manufacturing during growth decelerations. These findings suggest that changes in the allocation of resources lie behind changes in aggregate growth. But due to lacking sectoral data, they were unable to test this hypothesis.

In this story, growth accelerations and decelerations are decomposed into sectoral contributions using the modified shift-share analysis. ${ }^{22}$ For the decomposition we used all sectoral detail present in the GGDC 10-sector database, but in the results displayed below we aggregated up (after performing the shift-share analysis) to five sectors in order for the analysis to remain tractable. ${ }^{23}$ In Fig. 1 we present the contribution of each sector to aggregate growth averaged across the 19 developing countries in our data set. A distinction is made between periods of moderate growth, accelerations and decelerations.

Our benchmark case is periods of moderate aggregate growth. Moderate growth reflects "normal" growth in GDP per worker, between 0 and 3\%. In our data set, the average growth for such periods in developing countries is $1.8 \%$. The top panel of Fig. 1 presents average results from the shift-share decomposition for moderate growth periods. The figure reads as follows. Aggregate productivity growth in the total economy is given by the first column. This is divided into growth due to productivity growth within sectors (within), and to changes in employment share of sectors (between). The next columns indicate the percentage contribution of the five

\footnotetext{
${ }^{20}$ We extended the filter by examining growth decelerations as well. See the Appendix for details of the filter.

21 See e.g. Pritchett (2000), Hausmann et al. (2005) and Jones and Olken (2007).

22 A full set of decompositions by country is found in Table 3 (Appendix). Attention is restricted to labour productivity growth, since we do not have detailed sectoral capital data.

23 "Other industries" include mining, public utilities, and construction. "Market services" include wholesale and retail trade, transport and communication and financial services. "Non-market services" include community, social and personal services and government services. Note that some activities in non-market services are nevertheless traded through markets. For example many personal services, but also private education and health services should be part of "market services". However, our data is not detailed enough to distinguish market from non-market in these sectors. They are relatively small compared to the non-market part of this sector, although this will differ across countries and over time.
} 
sectors to aggregate growth again divided into a within- and a between-effect. The between-effect of each sector adds up to the total between-effect, and similarly for within-effects.

Several results are noticeable from the top panel. First, in periods of moderate advance, $75 \%$ of growth is due to productivity increases within sectors. About $25 \%$ of growth is due the expansion of more productive sectors (between-effect). Second, manufacturing is the main contributor to growth, but underlying the contribution of manufacturing is not so much its expansion but rather the productivity improvements within manufacturing. In contrast, the expansion of market services is principally responsible for the positive between-effect as market services expanded considerably and have higher productivity levels than the rest of the economy. ${ }^{24}$

During growth accelerations (second panel of Fig. 1), the within-sector contribution to growth increases. Average growth in GDP per worker during accelerations is $4.8 \%$ annually, which is for $79 \%$ explained by within-sector contributions, and for the remaining $21 \%$ by the expansion of more productive sectors. Hence, when growth accelerates the contribution from sectoral employment reallocation decreases in importance.

On average across all countries, improvements in agricultural productivity appear to have contributed little to accelerations in aggregate GDP per worker as indicated by the modest within-effect. However, looking at the country-specific contributions in Table 5 (Appendix), it follows that for two highly successful countries (South-Korea and Taiwan), a dynamic agricultural sector has been important for high growth.

Perhaps surprisingly, the main contributor to rapid increases in GDP per worker is market services and not manufacturing. Market services contribute approximately $39 \%$ of aggregate growth per worker, whereas manufacturing accounts for only $26 \%$. Hence, productivity improvements in market services are more important than productivity increases in manufacturing during growth accelerations. In part, increasing sectoral productivity might be due to increased capacity utilization, but given the longevity of many growth accelerations (14 years on average) it is more likely that this improvement is structural. Periods of acceleration are characterised by successful catching-up through imitation and transfers of technology from more advanced countries, which stimulates productivity growth within sectors.

Growth in GDP per worker declines by $2.7 \%$ points annually during periods of growth deceleration. A growth deceleration is associated with a dominant withineffect (bottom panel of Fig. 1). Market services are the main contributor to decelerations in GDP per worker, accounting for $53 \%$ of the decrease, mainly through a decline in productivity. As decelerations last shorter than upturns (8 years on average), the strong within-effect is likely due in part to large adjustment costs that reduce efficiency, rather than a secular decline. In addition, it is often acknowledged that during downturns displaced workers from manufacturing find new jobs in

\footnotetext{
24 This result is not due to use of a fixed base volume index. We rebased sectoral series each period and used mid-year prices for each period to minimize this problem. Unfortunately, rebasing periods is not possible for countries that experienced hyperinflation. In these instances, we aimed at mid-year base prices during the total time period covered (i.e. 1980 prices).
} 

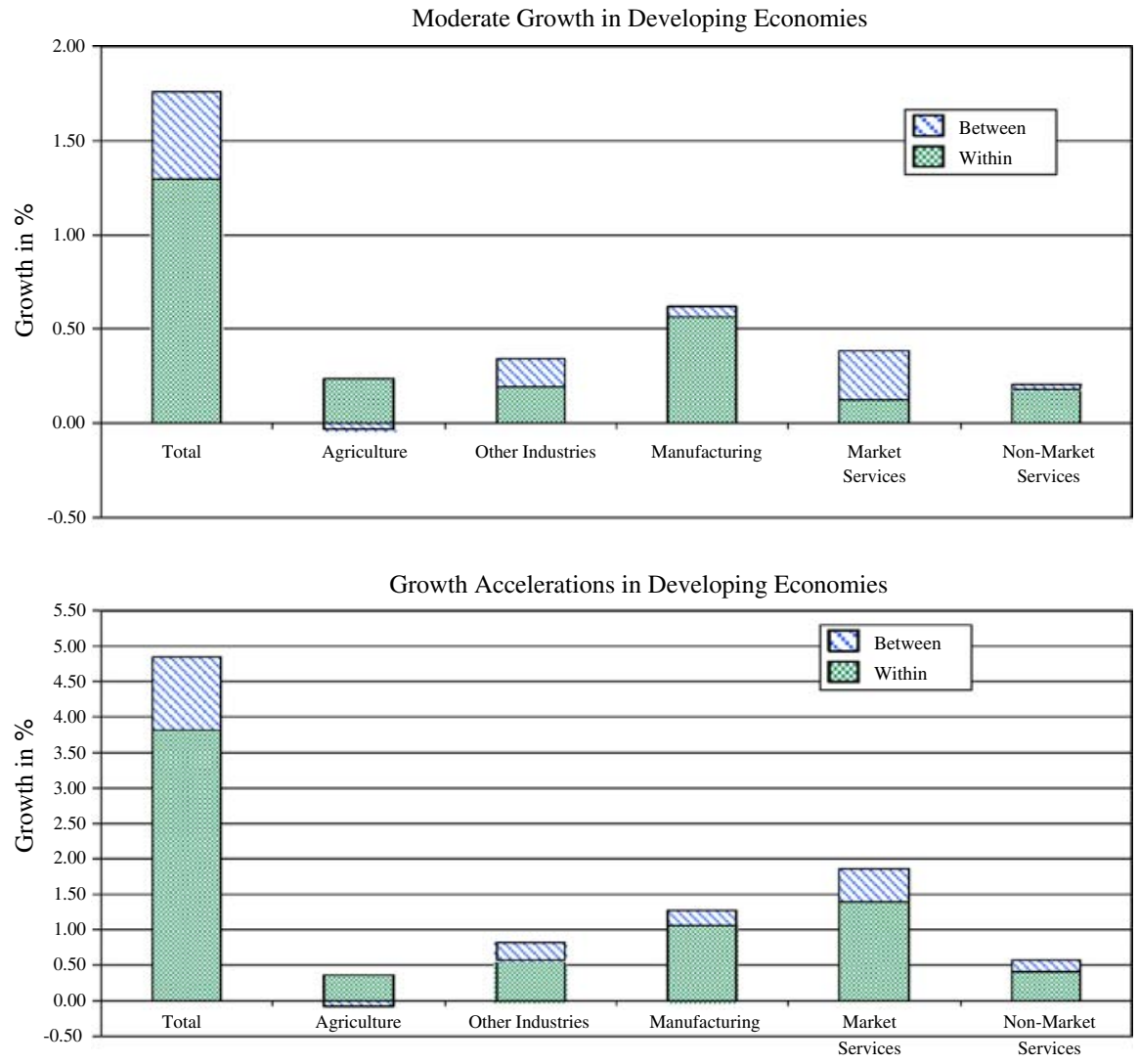

Growth Decelerations in Developing Economies

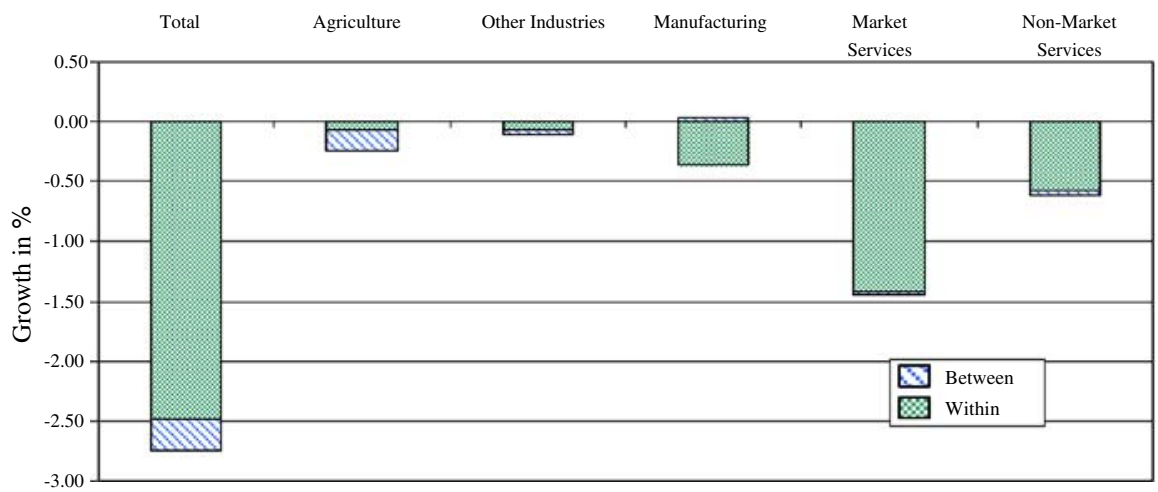

Fig. 1 Shift-share decomposition of accelerations and decelerations in labour productivity growth. Figures shown are averages across Asian and Latin American countries. A full set of country results is given in Table 4 (Appendix). (Source: authors' calculations based upon GGDC 10-sector database) 
agriculture and services (Jones and Olken 2008). Our results indeed show that the expansion of agriculture and services led to a negative shift-effect. Nevertheless, this shift-effect is small and explains only $9 \%$ of the decrease in GDP per worker.

\section{Conclusions}

In this paper we study the direct contribution of sectors to accelerations in economic growth. We propose two modifications to the standard shift-share analysis which make its results more useful. First, the standard method does not allow for disequilibria in factor markets in which average productivity differs from marginal productivity. We use estimates of the shadow price of labour to measure this wedge and adjust the shift-share methodology accordingly. Second, the standard method does not properly account for differences in productivity levels between sectors. We account for this and derive more meaningful measures of the contribution of a particular sector to aggregate productivity growth.

We use the modified shift-share analysis to decompose GDP per worker in developing countries during growth accelerations and decelerations. Our findings indicate that growth accelerations are largely explained by productivity increases within sectors. Market services and manufacturing are major contributors during accelerations, and market services appear to be the most important source. This challenges common wisdom regarding the lack of productivity growth in the services sector.

Still, a number of caveats should be raised. First, the decomposition method assumes constant returns to scale. Since we are not aware of sectoral studies that show increasing or decreasing returns to scale at the sector, we did not adjust the method accordingly. ${ }^{25}$ Second, the shift-share methodology is essentially a static method. A more dynamic analysis would recognise the endogeneity of structural change, induced by many factors including productivity growth within sectors, demand elasticities, trade patterns, and changes in world prices (see also Temple and Woessmann 2006). Our aim in this paper has been to measure the direct contribution of sectors in a simple model and we do not make claims about causality. Third, sectoral investment series are not included in the analysis. Because of this data constraint, we cannot decompose the movements in labour productivity into changes in capital intensity on the one hand and total factor productivity on the other. Further research on sectoral investment flows would be needed to resolve this issue. Fourth, in this paper we adjusted for surplus labour in agriculture. One can argue that in sectors like trade and transportation services, marginal and average productivity might diverge as well due to a significant amount of informal activities in poor countries. Ideally, this should be taken into account, but statistics on informal activities are scarce, especially at the sectoral level, and not comparable across countries. This remains an important issue for further research.

In this paper we also introduced the GGDC 10-sector database which is a new data set with time series of value added and persons employed for the ten main

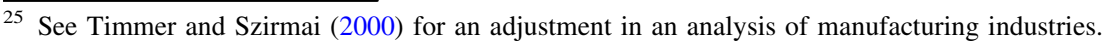


sectors of the economy. Although a series of adjustments have been made to ensure intertemporal and international consistency, major statistical problems remain. Productivity levels in agriculture in poor countries might be biased downward by systematic over-measurement of the labour input. Farm households are often engaged in both agricultural and non-agricultural activities. As we measure labour input in persons engaged, rather than hours, time devoted to each activity is not measured. Even more so, while agricultural labour input might be overestimated, output might be underestimated due to poor coverage of home-production destined for own-consumption. ${ }^{26}$ Also there are well-known output measurement problems for various market services industries, in particular finance and business services. And in many non-market services, output volumes are measured by an index of inputs, leading to zero productivity growth by construction (see e.g. Griliches 1992). Given the output measurement problems in services, our results should be considered with care. At a minimum, they indicate that market services play a more dynamic role in economic growth than hitherto acknowledged (see also Field 1996; Broadberry 2006) and that these industries deserve more attention in studies of the sectoral origins of aggregate growth.

Acknowledgments We would like to thank two anonymous referees, Bart van Ark, Dirk Bezemer, and Ewout Frankema for comments. We are grateful to André A. Hofman, Erik Monnikhof, and Nanno Mulder for their contribution to the construction of the GGDC 10-sector database.

Open Access This article is distributed under the terms of the Creative Commons Attribution Noncommercial License which permits any noncommercial use, distribution, and reproduction in any medium, provided the original author(s) and source are credited.

\section{Appendix}

Decomposition method

The contribution of a particular sector $i$ to aggregate labour productivity growth can be derived as follows. Let $C_{i}$ be the total contribution of sector $i$ to aggregate labour productivity growth:

$$
P^{T}-P^{0}=\sum_{i=1}^{n} C_{i}=\sum_{i=1}^{n}\left(C_{i}^{w}+C_{i}^{b}\right)
$$

where uppercase $w$ and $b$ denote within- and between-effects, respectively. We propose two improvements of the traditional shift-share analysis.

We account for the possibility that the marginal productivity is lower than the average productivity in agriculture at early stages of development. Let $\varepsilon_{\mathrm{A}}$ be the ratio of the marginal and average labour productivity of labour in the base year, being in between 0 and 1 . Then the average labour productivity level of the workers who are still in the agricultural sector at $T\left(\tilde{P}_{A}^{0}\right)$ can be written as follows:

\footnotetext{
$\overline{26}$ See e.g. Parente et al. (2000) and Schmitt (1989).
} 


$$
\begin{aligned}
\tilde{P}_{A}^{0}=\frac{Y_{\mathrm{A}}^{0}-\varepsilon_{\mathrm{A}} P_{\mathrm{A}}^{0}\left(L_{\mathrm{A}}^{0}-L_{\mathrm{A}}^{T}\right)}{L_{\mathrm{A}}^{T}} & \text { when } \quad L_{\mathrm{A}}^{T}-L_{\mathrm{A}}^{0}<0 \\
\tilde{P}_{\mathrm{A}}^{0}=P_{\mathrm{A}}^{0} & \text { otherwise }
\end{aligned}
$$

The contribution of agriculture to aggregate labour productivity growth is then defined as $\left(P^{T}-\tilde{P}^{0}\right) \bar{S}$. The remainder of the original within-contribution of agriculture, $\left(\tilde{P}^{0}-P^{0}\right) \bar{S}$, is distributed across those sectors that expand their labour shares in proportion to their share in total expansion.

Also, we examine the between-contribution of expanding sectors with productivity levels relative to shrinking sectors. Let $K$ be the set of expanding sectors, and $J$ the set of shrinking sectors. Then, as the sum of the increasing labour shares of expanding sectors is equal to the sum of the declining labour shares in shrinking sectors, aggregate labour productivity growth can be decomposed into sectoral contributions according to

$$
\begin{array}{ll}
C_{i}=C_{i}^{w}+C_{i}^{b}=\left(P_{i}^{T}-P_{i}^{0}\right) \bar{S}_{i}+\left(S_{i}^{T}-S_{i}^{0}\right)\left(\bar{P}_{i}-\bar{P}_{J}\right) \quad \forall i \in K \\
C_{i}=C_{i}^{w}=\left(P_{i}^{T}-P_{i}^{0}\right) \bar{S}_{i} \quad \forall i \in J
\end{array}
$$

with $\bar{P}_{J}$ the labour productivity averaged over all shrinking sectors $j \varepsilon J$ :

$$
\bar{P}_{J}=\frac{\sum_{i \in J}\left(S_{i}^{T}-S_{i}^{0}\right) \bar{P}}{\sum_{i \in J}\left(S_{i}^{T}-S_{i}^{0}\right)}
$$

The implication of this reallocation of sectors is that growing sectors get credited for the between-effect. This between-effect is positive when an expanding sector's productivity $\left(P_{i}\right.$ with for all $\left.i \in K\right)$ is higher than the average productivity of the shrinking sectors $\left(\bar{P}_{J}\right)$. But it can also be negative when the expanding sector's productivity is lower than the average productivity of the shrinking sectors.

Combining the equations above, the contributions of individual sectors to aggregate labour productivity growth can be determined as follows:

$$
\begin{aligned}
& C_{i}=C_{i}^{b}+C_{i}^{w} \\
& C_{i}^{b}=\left(P_{i}^{T}-P_{i}^{0}\right) \bar{S}_{i} \quad \forall i \neq A \\
& C_{A}^{b}=\left(P_{A}^{T}-\tilde{P}_{A}^{T}\right) \bar{S}_{\mathrm{A}} \\
& C_{i}^{w}=0 \quad \forall i \in J \\
& C_{i}^{w}=\left(S_{i}^{T}-S_{i}^{0}\right)\left(\bar{P}_{i}-\bar{P}_{J}\right) \quad \forall i \in K \text { when } L_{\mathrm{A}}^{T}-L_{\mathrm{A}}^{0} \geq 0 \\
& C_{i}^{w}=\left(S_{i}^{T}-S_{i}^{0}\right)\left(\bar{P}_{i}-\bar{P}_{J}\right)+\frac{\left(S_{i}^{T}-S_{i}^{0}\right)}{\sum_{i \in K}\left(S_{i}^{T}-S_{i}^{0}\right)}\left(\tilde{P}_{A}^{T}-P_{A}^{0}\right) \bar{S}_{A} \quad \forall i \in K \\
& \text { when } L_{\mathrm{A}}^{T}-L_{\mathrm{A}}^{0}<0
\end{aligned}
$$

Derivation of marginal productivity of labour in agriculture

We use country-specific shadow shares of labour in agriculture to estimate surplus labour. Coelli and Rao (2005) show that data envelopment analysis (DEA) ${ }^{27}$ implicitly

\footnotetext{
27 DEA is a linear programming method, which uses input and output data to construct a piecewise linear production frontier over the data points.
} 
delivers shadow price information in estimating the global production frontier. The shadow price of labour reflects the marginal productivity of labour. Coelli and Rao (2005) present shadow shares of labour input (see Table 10 in their paper), defined as:

$$
\alpha_{\mathrm{s}}=\frac{w_{\mathrm{s}} L}{Y} \Leftrightarrow w_{\mathrm{s}}=\frac{\alpha_{\mathrm{s}} Y}{L}
$$

where $\alpha_{\mathrm{s}}$ is the shadow share of labour, $w_{\mathrm{s}}$ the shadow price or marginal productivity of labour, $L$ the economically active population in agriculture, and $Y$ nominal agricultural output. We let $w$ represent the average wage or average productivity of labour, which is equal to labour compensation divided by employment. The ratio of marginal to average productivity, $\varepsilon$, is therefore:

$$
\varepsilon=\frac{w_{\mathrm{s}}}{w}=\frac{\left(\frac{\alpha_{\mathrm{s}} Y}{L}\right)}{\left(\frac{\alpha Y}{L}\right)}=\frac{\alpha_{\mathrm{s}}}{\alpha}
$$

The share of labour compensation in nominal agricultural output, $\alpha$, is assumed to equal 0.9. Table 3 shows the estimated country-specific ratio of marginal to average productivity in Asia and Latin America.

Table 3 Ratio of marginal to average productivity

$\varepsilon$ is the ratio of marginal to average productivity

${ }^{a}$ Due to missing observations we used the cross-country average ratio for Hong Kong, Japan, Singapore, and Taiwan

\begin{tabular}{ll}
\hline Country & $\varepsilon$ \\
\hline Argentina & 0.521 \\
Bolivia & 0.389 \\
Brazil & 0.368 \\
Chile & 0.290 \\
Colombia & 0.392 \\
Costa Rica & 0.326 \\
Hong Kong $^{\text {a }}$ & 0.304 \\
Indonesia $^{\text {India }}$ & 0.469 \\
Japan $^{\mathrm{a}}$ & 0.494 \\
Korea & 0.304 \\
Mexico $^{\text {Malaysia }}$ & 0.156 \\
Peru $_{\text {Philippines }}$ & 0.356 \\
Singapore $^{\mathrm{a}}$ & 0.242 \\
Thailand $^{\mathrm{Taiwan}}{ }^{\mathrm{a}}$ & 0.410 \\
Venezuela & 0.311 \\
\hline & 0.304 \\
& 0.676 \\
& 0.304 \\
& 0.161 \\
\hline
\end{tabular}


Selecting accelerations and decelerations in economic growth

The filter introduced by Hausmann et al. (2005) is used to select accelerations and decelerations in GDP per worker. ${ }^{28}$ This filter is constructed as follows. First, the change in the growth of GDP per worker $g$ at time $T$ is the change in growth over 5year periods, ${ }^{29}$ given by:

$$
\Delta g_{T, 5}=\bar{g}_{T, T+5}-\bar{g}_{T-5, T}
$$

Next, we identify the following growth regime whenever:

(1) $\bar{g}_{0, T} \geq 3 \%$ Growth acceleration

(2) $\bar{g}_{0, T} \leq 0 \%$ Growth deceleration

Time starts at 0 , the beginning of the growth regime and stops at $T$, the end of the growth period. Identification of a growth period in year $t$ is subject to the following conditions:
s.t. $\Delta g_{t, n} \geq|3 \%|$
A considerable change in the 5-year average linear growth rate
s.t. either $y_{T} \leq \max \left(y_{i}\right), i<T$ Post-acceleration output per worker exceeds pre- episode peak
or $y_{T} \leq \max \left(y_{i}\right), i<T$
Post-deceleration output per worker is below pre- episode peak

This filter identifies two growth periods (that is accelerations and decelerations), and moderate growth refers to periods where there is no acceleration or deceleration in growth. The significance of changes in growth periods that we found in our data set are further tested using spline regression analysis. All changes are significant at the $1 \%$ level, and we selected the year with the highest test significance if the filter identifies consecutive years as a break year.

In addition to the filter, we also look at the average growth before a break in GDP per worker occurs. If growth is above $3 \%$ per annum, or below $0 \%$ this period is also selected as an acceleration or deceleration. This addition to the filter is relevant for several Asian countries that experienced an uninterrupted acceleration in GDP per worker throughout our data set (i.e. Korea and Taiwan). Table 4 shows the resulting growth periods in Asia and Latin America. Table 5 shows the country results from the decompositions of the distinctive growth periods.

\footnotetext{
${ }^{28}$ Our filter is somewhat different from the filter introduced by Hausmann et al. (2005). We extended the filter to incorporate growth decelerations. Some parameters of the filter are slightly different. The time horizon is shorter which increases the possibility of finding a growth acceleration and deceleration, but the identification of a growth regime is stricter reducing the possibilities. To some extent both effects cancel out.

29 A 5-year horizon is chosen in order to mitigate business cycle effects. We study linear growth rates for consistency in this paper. The shift-share analysis decomposes linear growth. Following Easterly et al. (1993) we could also use growth rates from the logarithm of GDP per worker, or we could follow Jones and Olken (2007) and Hausmann et al. (2005) and estimate growth rates as the least square average. Alternative estimates of growth rates only give slightly different results.
} 
Table 4 Start of accelerations and decelerations in Asia and Latin America

\begin{tabular}{|c|c|c|c|}
\hline \multirow[t]{2}{*}{ Country } & \multicolumn{3}{|l|}{ Year of break by type } \\
\hline & Growth acceleration & Moderate growth & Growth deceleration \\
\hline Hong Kong & 1975,1998 & 1993 & \\
\hline India & 1979 & 1960 & 1970 \\
\hline Indonesia & 1970,2001 & & 1996 \\
\hline Japan & 1960 & 1990 & \\
\hline Republic of Korea & 1963 & & \\
\hline Malaysia & 1975 & 1997 & \\
\hline Philippines & 1971 & 1986 & 1976 \\
\hline Singapore & 1970 & 1996 & \\
\hline Taiwan (China) & 1963 & & \\
\hline Thailand & 1961,1985 & 1979,2001 & 1996 \\
\hline Argentina & 1990 & 1950 & 1980, 1998 \\
\hline Bolivia & 1950, 1959 & 1969, 1987 & 1954, 1982 \\
\hline Brazil & 1950,1966 & 1961, 1992 & 1980 \\
\hline Chile & 1976,1985 & 1950, 1997 & 1971,1981 \\
\hline Colombia & 1993 & 1950,2001 & 1987, 1997 \\
\hline Costa Rica & 1950 & 1958 & \\
\hline Mexico & 1950, 1977 & 1957, 1988 & 1981 \\
\hline Peru & 1960, 1991, 1999 & 1983 & $1974,1987,1995$ \\
\hline Venezuela & 1950 & 1988,2001 & 1957, 1992 \\
\hline
\end{tabular}

Start of acceleration and deceleration is estimated using the extended filter from Hausmann et al. (2005), described above 


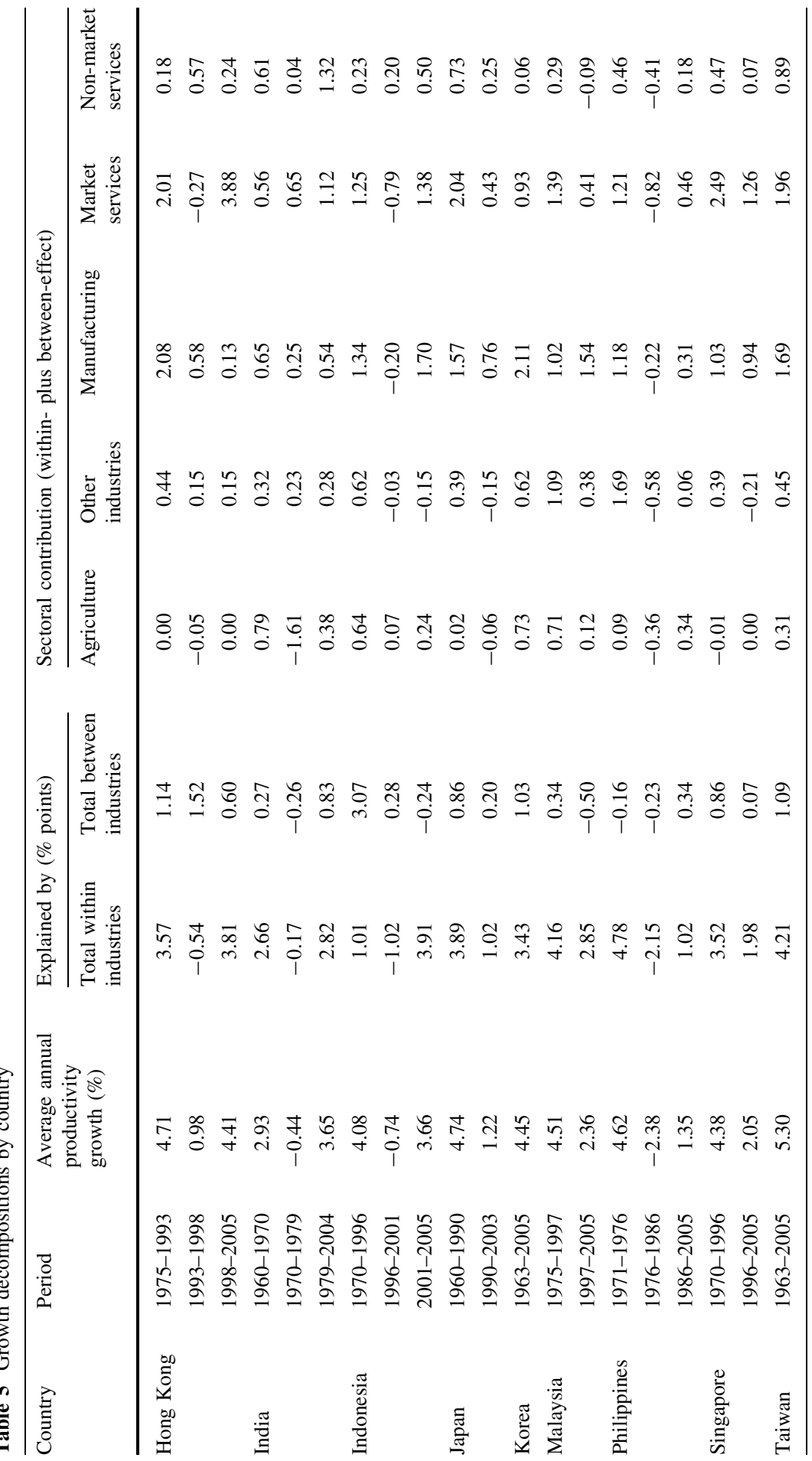




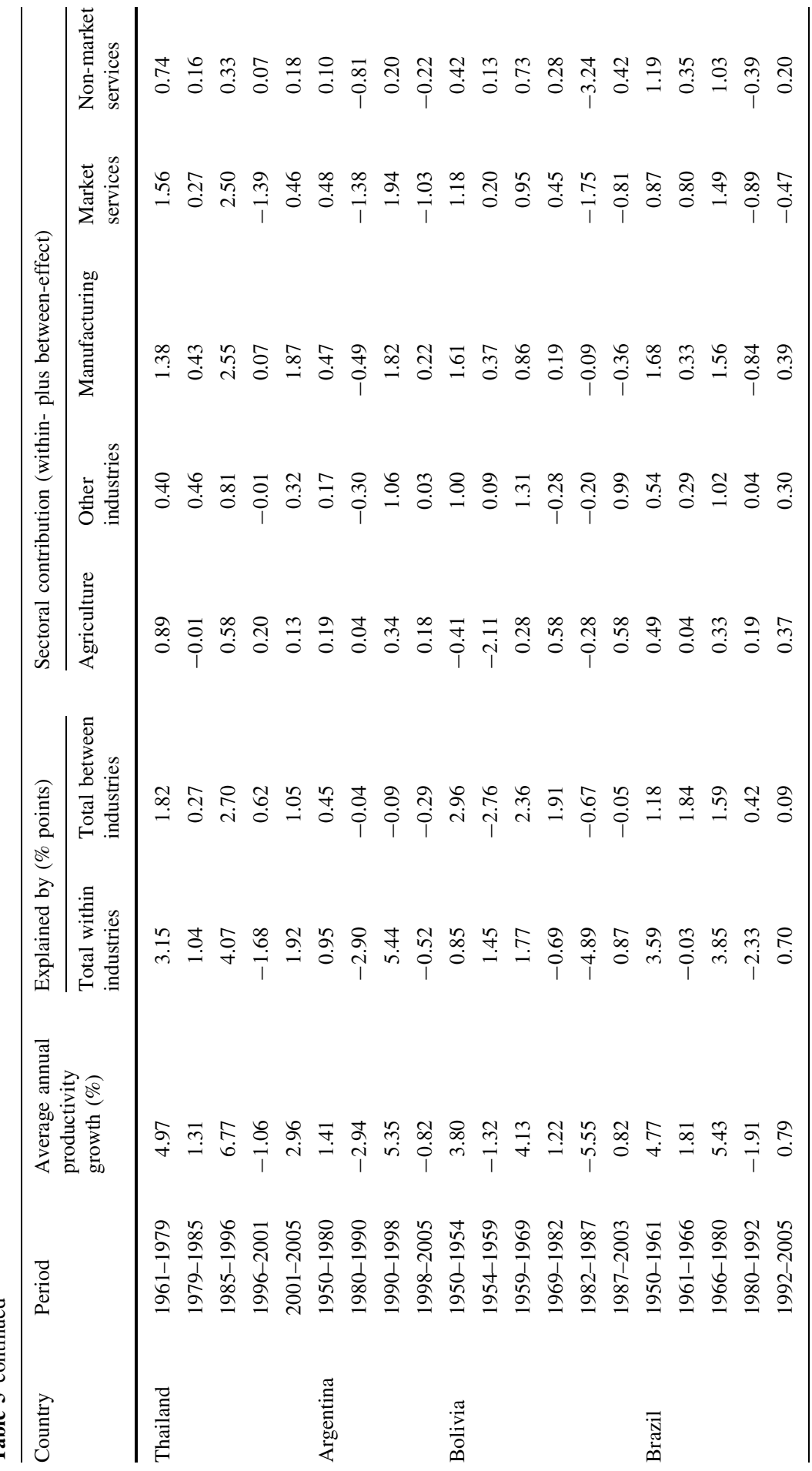




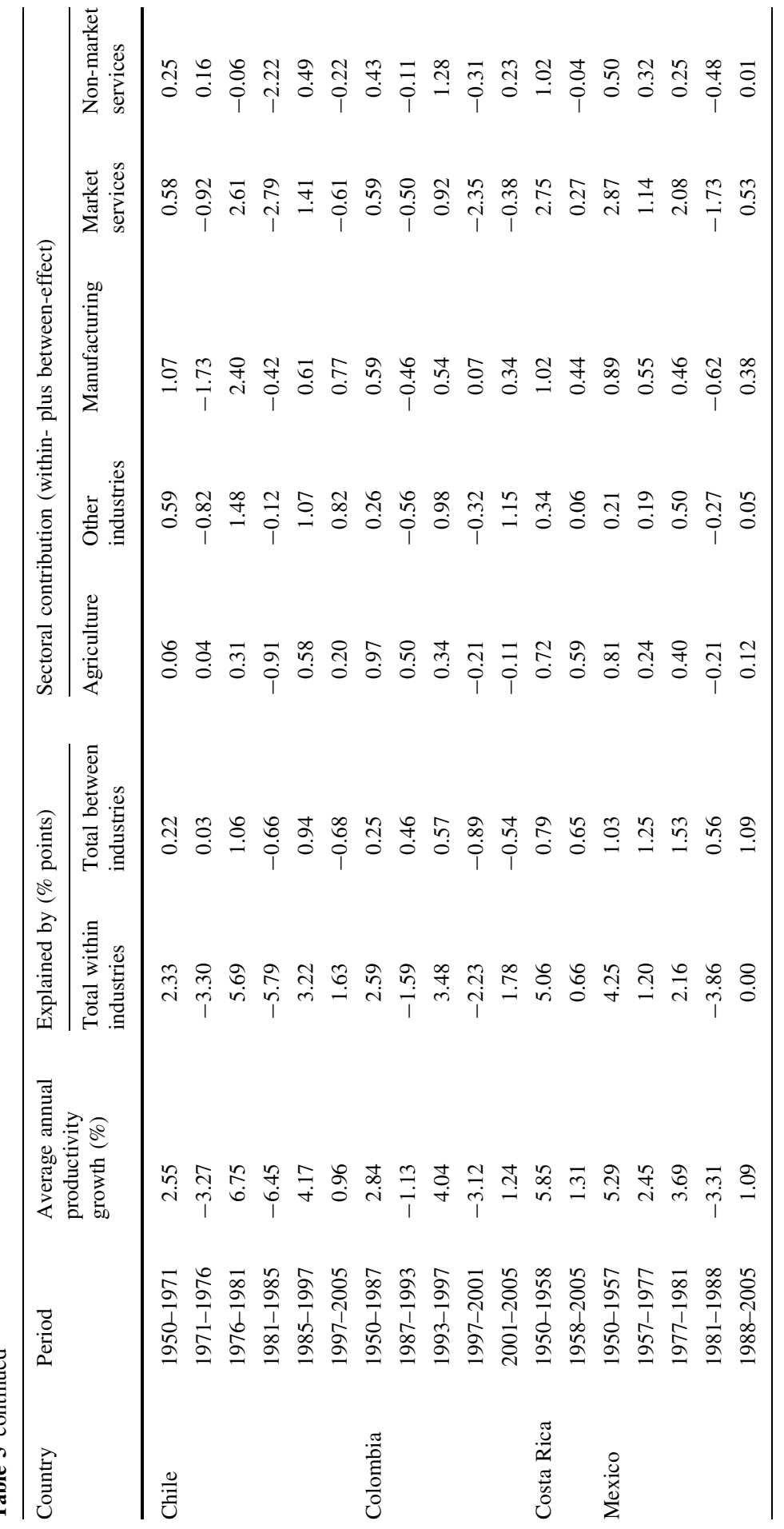




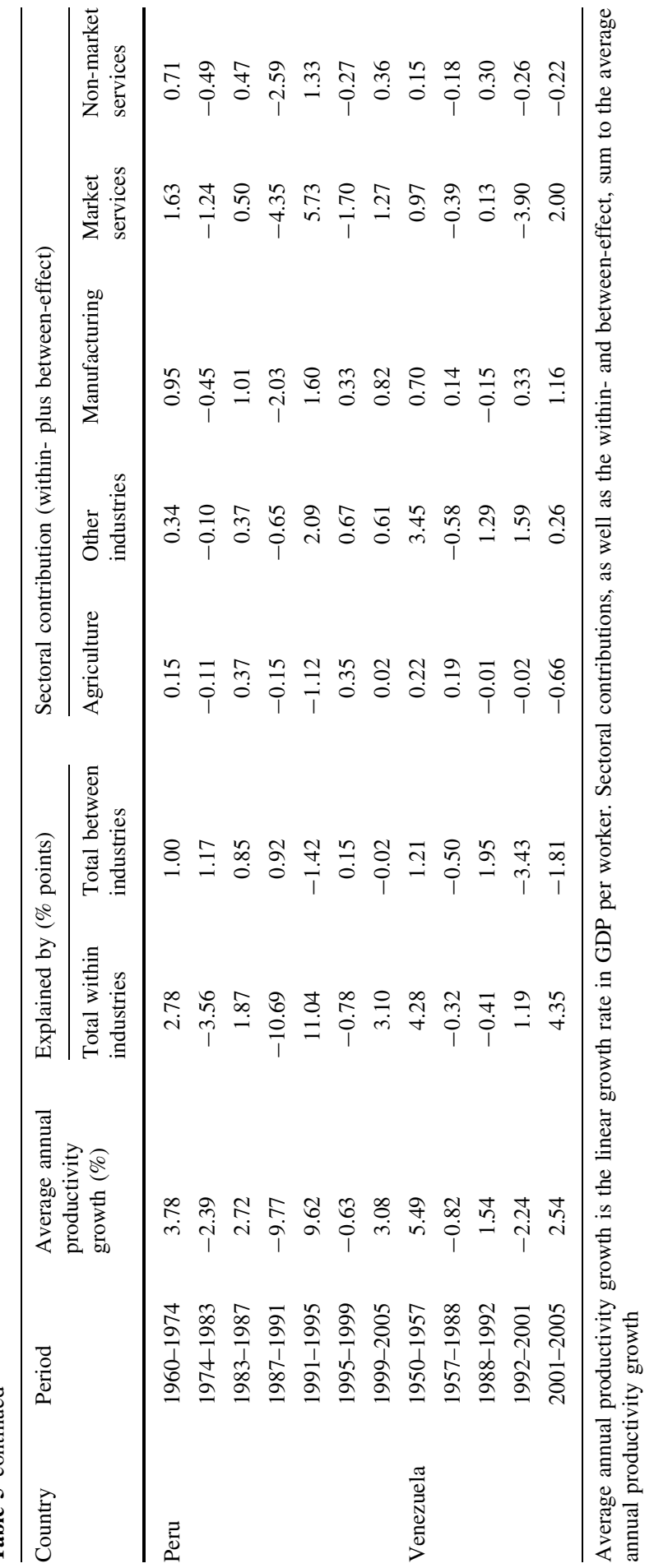




\section{References}

Booth A (2003) The Broadberry-Crafts view and evidence: a reply. Econ Hist Rev 56:736-742

Broadberry SN (1998) How did the United States and Germany overtake Britain?: a sectoral analysis of comparative productivity levels, 1870-1990. J Econ His 58:375-407

Broadberry SN (2006) Market services and the productivity race, 1850-2000: British performance in international perspective. Cambridge University Press, Cambridge

Broadberry SN, Crafts NFR (2003) UK productivity performance from 1950 to 1979: a restatement of the Broadberry-Crafts view. Econ Hist Rev 56:718-735

Chenery H, Robinson S, Syrquin M (1986) Industrialization and growth: a comparative study. Oxford University Press, New York

Coelli TJ, Rao DSP (2005) Total factor productivity growth in agriculture: a Malmquist index analysis of 93 countries, 1980-2000. Agric Econ 32:115-134

Crafts NFR (1984) Patterns of development in nineteenth century Europe. Oxf Econ Pap 36:438-458

Crafts NFR (1993) Can de-industrialisation seriously damage your wealth? Hobart Paper 120

Denison EF (1967) Why growth rates differ. Washington DC, Brookings

Easterly W, Kremer M, Pritchett L, Summers LH (1993) Good policy or good luck? Country growth performance and temporary shocks. J Monet Econ 32:459-83

Fabricant S (1942) Employment in manufacturing, 1899-1939. NBER, New York

Fei JCH, Ranis G (1964) Development of the labour surplus economy. Irwin, Homewood

Fei JCH, Ranis G (1997) Growth and development from an evolutionary perspective. Blackwell, London

Field AJ (1996) The relative productivity of American distribution, 1869-1992. Res Econ His 16:1-37

Field AJ (2006) Technological change and U.S. economic growth in the interwar years. J Econ His 66:203-236

Griliches Z (1992) Output measurement in the service sectors. In: Grilliches Z (ed) NBER studies in income and wealth, vol 56. University of Chicago Press, Chicago

Harberger A (1998) A vision of the growth process. Am Econ Rev 88:1-32

Hausmann R, Pritchett L, Rodrik D (2005) Growth accelerations. J Econ Growth 10:303-329

Jones BF, Olken BA (2008) The anatomy of start-stop growth. Rev Econ Stat (in press)

Kuznets S (1966) Modern economic growth: rate, structure and spread. Yale University Press, London

Lewis WA (1954) Economic development with unlimited supplies of labour. Manchester Sch Econ Soc Stud 22:139-191

Maddison A (1987) Growth and slowdown in advanced capitalist economies: techniques of quantitative assessment. J Econ Lit 25:649-698

Maddison A (2003) The world economy: a millennial perspective. OECD Development Centre, Paris

Parente SL, Rogerson R, Wright R (2000) Homework in development economics: household production and the wealth of nations. J Polit Econ 108:680-687

PREALC (1982) Mercado de trabajo en cifras. ILO, PREALC

Pritchett L (2000) Understanding patterns of economic growth: searching for hills among plateaus, mountains and plains. World Bank Econ Rev 14:221-250

Rosenzweig M (1988) Labour markets in low-income countries. In: Chenery HB, Srinivasan TN (eds) Handbook of development economics. North-Holland, Amsterdam

Salter WEG (1960) Productivity and technical change. Cambridge University Press, New York

Schmitt G (1989) Simon Kuznets' "sectoral shares in labour force": a different explanation of his $(I+S) / A$ ratio. Am Econ Rev 79:1262-1276

Syrquin M (1984) Resource allocation and productivity growth. In: Syrquin M, Taylor L, Westphal LE (eds) Economic structure and performance. Essays in honour of Hollis B. Chenery. Academic Press, Orlando

Temin P (2002) The golden age of European growth reconsidered. Eur Rev Econ Hist 6:3-22

Temple J, Woessmann L (2006) Dualism and cross-country growth regressions. J Econ Growth 11:187-228

Timmer MP, Szirmai A (2000) Productivity growth in Asian manufacturing: the structural bonus hypothesis re-examined. Struct Change Econ Dyn 11:371-391

Timmer MP, de Vries GJ (2007) A cross-country database for sectoral employment and productivity in Asia and Latin America, 1950-2005. GGDC Research Memorandum 98

Van Ark HH (1996) Sectoral growth accounting and structural change in post-war Europe. In: van Ark $\mathrm{HH}$, Crafts NFR (eds) Quantitative aspects of post-war European economic growth. CEPR, Cambridge University Press, Cambridge 